Moraes, E.A.; Irving, M.A. Ecoturismo: encontros e desencontros na Reserva Extrativista do Cazumbá-Iracema (AC). Revista Brasileira de Ecoturismo, São Paulo, v.6, n.3, ago/out2013, pp.738-757.

\title{
Ecoturismo: encontros e desencontros na Reserva Extrativista do Cazumbá-Iracema (AC)
}

\author{
Ecotourism: agreements and disagreements in Extractive Reserve \\ Cazumbá-Iracema (AC, Brazil)
}

\section{Edilaine Albertino de Moraes, Marta de Azevedo Irving}

\section{RESUMO}

O ecoturismo tem sido interpretado como uma alternativa possível para o desenvolvimento local em associação às Unidades de Conservação. Para a categoria de manejo de UC Reserva Extrativista, especialmente na Amazônia brasileira, o ecoturismo tem sido discutido também como possibilidade de uso múltiplo dos recursos florestais. Com este enfoque, este artigo busca analisar como os moradores do Núcleo do Cazumbá (Reserva Extrativista do Cazumbá-Iracema - Acre) interpretam o ecoturismo, em seu panorama atual e futuro. A metodologia baseou-se em pesquisa bibliográfica e documental, observação participante, realização de entrevistas semiestruturadas e projetivas e rodas de conversa com os interlocutores selecionados. Os principais resultados obtidos revelaram que os interlocutores da pesquisa entendem o ecoturismo como potencialidade para o desenvolvimento local, em uma perspectiva de longo prazo. Mas para tal, é ainda necessária a sua mobilização e organização, a partir da decisão coletiva e do controle social do processo de planejamento e de implementação do ecoturismo, com o compromisso de melhoria da qualidade de vida e proteção do patrimônio natural e cultural .

PALAVRAS-CHAVE: Ecoturismo; Unidades de Conservação; Reserva Extrativista do Cazumbá-Iracema.

\section{ABSTRACT}

Ecotourism has been interpreted as a possible alternative for local development in association with Protected Areas. For the category Extractive Reserve, especially in the Brazilian Amazon, ecotourism has also been discussed as possibility of multiple use of forest resources. With this approach, this paper analyzes how the residents of the Core Cazumbá (Extractive Reserve Cazumbá-Iracema - Acre) interpret ecotourism in their current situation and future. The methodology was based on literature and documents, participant observation, semi-structured interview, projective technique and through conversations with selected partners. The main results showed that the research partners understand how ecotourism potential for local development in a long-term perspective. But to do so, it is still necessary to their mobilization and organization, from the collective decision and social control of the process of planning and implementation of ecotourism, with a commitment to improving the quality of life and protection of natural and cultural heritage.

KEYWORDS: Ecotourism; Protected Areas; Extractivist Reserve Cazumbá-Iracema. 


\section{Introduzindo o tema}

A proposta de Reserva Extrativista (RESEX) se originou no Movimento Seringueiro, na década 1980, no Estado brasileiro do Acre. Este modelo de uso do território foi concebido sob a lógica de integração sociedade e natureza, para a conservação dos recursos naturais e a proteção dos modos de vida e da cultura das populações tradicionais. Por sua origem, a categoria de manejo de Unidade de Conservação RESEX é defendida por vários segmentos da sociedade civil organizada, como uma alternativa para o desenvolvimento social, econômico e cultural da Amazônia brasileira.

Consideradas como Unidades de Conservação (UCs) de Uso Sustentável pelo Sistema Nacional de Unidades de Conservação - SNUC (BRASIL, 2000, 2002), as RESEX são baseadas na economia extrativista, que orienta o uso múltiplo dos recursos naturais. Mas o processo de implementação dessas UCs é complexo e requer novas alternativas econômicas e tecnologias conjugadas a estudos de mercado, que considerem a dinâmica socioambiental nessas áreas naturais protegidas. Sendo assim, o processo de implementação de uma RESEX é lento e dependente de organização social e política, além de demandar recursos financeiros para o fortalecimento das cadeias produtivas extrativistas (ALEGRETTI, 2004). Mas mesmo diante das dificuldades de implementação dessas UCs, é possível notar que, desde o seu surgimento, várias iniciativas têm sido realizadas para a expansão dessa categoria de manejo em todo o território nacional.

Um importante argumento para o reconhecimento e a difusão desta categoria de manejo de UC, segundo Murrieta e Rueda (1995), reside na possibilidade de uso múltiplo da floresta, por meio do aproveitamento das potencialidades de sua biodiversidade. Com este enfoque, a possibilidade de uso múltiplo da floresta, e a prática do ecoturismo em particular, tendem a representar importantes alternativas econômicas para o fortalecimento da cultura local e para a redução da pressão sobre os recursos naturais renováveis (MORAES; IRVING, 2007).

Mas considerando que as primeiras RESEX surgiram na Amazônia brasileira, é importante entender que, o ecoturismo nessa região tem sido desenvolvido dissociado de estratégias de planejamento centradas em uma discussão ética sobre sustentabilidade, o que vem colocando, frequentemente em risco, a proteção do patrimônio natural e cultural da região, causando crescentes impactos e exclusão das populações locais. Em realidade, pode-se interpretar que o ecoturismo na região é, em geral, sazonal e se limita à hospedagem em "hotéis de selva" e a algumas excursões pelos rios amazônicos. Mas a dificuldade de acesso, o custo, a limitação de infraestrutura em algumas localidades, e até mesmo o receio dos visitantes pelos efeitos de doenças tropicais, como a malária, são justificativas constantemente citadas como problemas ao uso turístico da região. E de forma contrastante a estes problemas, o apelo à proposta de ecoturismo na Amazônia decorre da percepção associada ao seu elevado valor ecológico (capital natural) e também ao seu valor simbólico, no plano global.

Frases como "Ecoturismo: Desbrave a beleza selvagem da Amazônia"1 são, frequentemente, utilizadas em peças publicitárias de pacotes de viagens à região, com forte inspiração no "mito moderno da natureza intocada"2. Mas apesar deste ape- 
lo, alguns pesquisadores acreditam que o turismo pode ser prejudicial à região, tendo em vista os impactos possíveis decorrentes da exploração de mão de obra e da base de recursos naturais e culturais, estes entendidos apenas como atrativos. Outros percebem o ecoturismo como uma alternativa possível para a proteção da biodiversidade. Ou seja, a noção de ecoturismo, na região, é marcada por sentidos distintos, sobretudo, com relação aos inúmeros significados e subjetividades vinculados à biodiversidade amazônica.

E razões diversas impedem o avanço dessa prática, tal como argumenta Irving (2006, p.46), para a qual o ecoturismo na Amazônia brasileira representa ainda uma "projeção distante na economia local, como uma possibilidade remota no mundo globalizado". No entanto, esta é uma questão central para a reflexão acadêmica e para o contexto atual de políticas públicas, quando se discutem alternativas "sustentáveis" para a subsistência e a inserção das populações amazônicas na cadeia produtiva regional.

É no sentido de contribuir para esta reflexão, que este artigo tem como foco a interpretação do ecoturismo sob a ótica local, na Reserva Extrativista do CazumbáIracema, localizada em Sena Madureira (AC). Esta Resex é considerada uma importante unidade de conservação federal por abrigar uma amostra expressiva da sociobiodiversidade amazônica. Com este intuito, o artigo busca interpretar as percepções dos atores locais e interlocutores institucionais sobre o ecoturismo como alternativa possível para o desenvolvimento local.

Para tanto, os caminhos metodológicos de pesquisa se fundamentaram, basicamente, em revisão bibliográfica e documental, e levantamentos de campo. Os recursos metodológicos da pesquisa de campo foram: roteiro de entrevista semiestruturada e projetiva, observação participante e rodas de conversa.

A maioria das entrevistas foi dirigida a alguns moradores locais, os quais foram selecionados por meio da técnica "bola de neve"3 (LINCOLN; GUBA, 1985 apud ALVES-MAZZOTTI; GEWANDSZNAJDER, 2004, p.163). Sob essa orientação, os sujeitos entrevistados e participantes das rodas de conversa foram 19 residentes fixos do Núcleo do Cazumbá, que participaram do processo de luta pela criação da Reserva Extrativista, e estiveram envolvidos na implementação das primeiras pousadas no local, com papéis reconhecidos de liderança na organização das atividades cotidianas locais. Algumas entrevistas foram direcionadas a oito interlocutores institucionais estratégicos com atuação reconhecida nas ações ambiental e turística na área de influência da unidade de conservação. Neste caso, foram entrevistados os representantes do Escritório Regional do Instituto Chico Mendes da Conservação da Biodiversidade ICMBIO em Sena Madureira ${ }^{4}$; da Secretaria Municipal de Meio Ambiente de Sena Madureira - SEMA; do World Wildelife Found - WWF-BR (escritório de Rio Branco/AC), da Secretaria de Esporte, Turismo e Lazer do Estado do Acre, da Diretoria de Unidades de Conservação de Uso Sustentável ${ }^{5}$ - DIUSP/ICMBIO/MMA, da coordenação do Programa de Desenvolvimento do Ecoturismo na Amazônia Legal - PROECOTUR/ PNE/MMA, do Conselho Nacional dos Seringueiros - CNS, e do Grupo de Trabalho Amazônico - GTA. A sistematização e a análise dos dados obtidos foram realizadas 
por meio de uma adaptação da Análise de Conteúdo de Bardin (1994). Este processo envolveu a ordenação temática dos trechos das entrevistas, com relação ao contexto do ecoturismo em seu panorama atual (significado, potencialidades, benefícios esperados, impactos indesejáveis e obstáculos) e em uma perspectiva futura (demandas locais, interesse de participação no processo e desafios).

Sob esta abordagem, o artigo está estruturado em duas seções principais. A primeira aborda a fundamentação teórica norteadora para esta reflexão, envolvendo as principais questões conceituais sobre ecoturismo em unidades de conservação, na contemporaneidade, para orientar a análise do caso específico das Reservas Extrativistas, em seus princípios e relevância no contexto amazônico. Em seguida, busca-se caracterizar a Reserva Extrativista do Cazumbá-Iracema, considerando-se o seu contexto socioambiental e a percepção sobre o ecoturismo, através da voz dos seus protagonistas, os moradores locais, sendo esta análise complementada pela leitura institucional sobre o tema.

\section{Ecoturismo em Unidades de Conservação: Questões conceituais norteadoras}

A noção de ecoturismo, tal como se discute na contemporaneidade, surge a partir do despertar da sociedade global para a proteção da natureza, a partir das décadas de 1970 e $1980^{6}$. E desde então, na sociedade contemporânea, a "natureza intocada" torna-se pretexto para a descoberta, a aprendizagem e o espírito de aventura, sendo também apropriada como argumento valioso de mercado. Nesta percepção, a noção de ecoturismo, em sua origem, teve como inspiração o processo das viagens dirigidas ao ambiente natural preservado, sendo, progressivamente, ressignificada como uma possibilidade de uso sustentável dos recursos naturais renováveis, através de uma nova concepção de turismo ${ }^{7}$.

Seguindo esta perspectiva, diversos estudiosos destacam um aumento progressivo de turistas, cada vez mais interessados em conhecer destinos ligados à natureza preservada, como alternativa às formas convencionais de lazer e viagens. $E$ a partir desta tendência pelo contato com a natureza, as empresas turísticas passam a entendê-la como uma grande oportunidade de negócio. Desta forma, os destinos turísticos associados à "natureza preservada", qualificados pelo "eco", passam a representar uma oportunidade em termos de diferencial competitivo de mercado.

Assim, Pires (2002) menciona que o aumento de demanda pelo ecoturismo se acentua, sobretudo a partir da década 1990, atingindo países da América Latina (como o Brasil), África e Ásia, e principalmente, os países pioneiros nesta prática, como o Peru, Costa Rica, Senegal e Suriname. Paralelamente a este movimento, parece também evidente um crescente interesse pelo tema, por parte da esfera governamental, principalmente, nos países em desenvolvimento, que apostam na potencialidade do ecoturismo para a geração de renda e emprego, além de estratégia possível para a proteção da biodiversidade. Da mesma forma, as organizações não governamentais, sobretudo, aquelas de cunho ambientalista, passam a se interessar por este processo e, a se inserir, cada vez mais, na discussão sobre ecoturismo.

Para a União Internacional para a Conservação da Natureza (UICN): 
Ecoturismo consiste em viagens ambientalmente responsáveis com visitas a áreas naturais relativamente sem distúrbios, para desfrutar e apreciar a natureza, juntamente com as manifestações culturais do passado ou do presente que possam existir, e que ao mesmo tempo promove a conservação, proporciona baixo impacto pelos visitantes e contribui positivamente para o envolvimento socioeconômico ativo das populações locais (CEBALLOS-LASCURÁIN, 2002, p.27).

Seguindo esta linha conceitual, a importância econômica, social e ambiental do ecoturismo tem sido reconhecida, em nível mundial, com a designação de 2002, como o Ano Internacional do Ecoturismo, pela Organização das Nações Unidas (ONU), com o apoio da Organização Mundial de Turismo. No mesmo ano, foi oficializada, durante a Cúpula Mundial Rio+10, a Declaração de Quebéc, documento norteador para o ecoturismo no mundo, com o objetivo de estimular governos, o setor empresarial, populações receptoras e os próprios turistas a dedicarem esforços para que o ecoturismo se consolide como uma alternativa viável para o desenvolvimento local ${ }^{8}$ e melhoria de qualidade de vida dos grupos humanos diretamente envolvidos no processo.

Mas anos antes da Declaração de Quebéc, em 1994, no Brasil, já haviam sido elaboradas as "Diretrizes para uma Política Nacional de Ecoturismo" pelo Grupo de Trabalho Interministerial em Ecoturismo (Ministério da Indústria, Comércio e Turismo e o Ministério do Meio Ambiente e da Amazônia Legal), entendendo ser esta uma alternativa que compatibiliza, em tese, a proteção do patrimônio natural e cultural, incentiva a sua conservação, promove a formação de uma consciência ambientalista e o bem-estar das populações envolvidas (BRASIL, 1994).

Apesar disso e mesmo considerando o ecoturismo sob a ótica dos discursos oficiais, Fennel (2002, p.175) o define como um processo "reembalado e produzido em massa, na expectativa de aumentar a sua participação no mercado". Complementando o debate, Irving (2008) assinala que, é nesse movimento que emerge um perfil de demanda elitizada, associado a um público capitalizado e disposto a pagar pelo "encontro" com o ambiente natural, "inflacionado" pela crescente comoditização da natureza.

Contudo, como se pensar as tendências para o ecoturismo no Brasil no século XXI? No ranking de países mais visitados em 2011, segundo avaliação do Fórum Econômico Mundial, o país ocupou apenas a $52^{\underline{a}}$ posição, mas alcançou o $7^{\circ}$ lugar nas Américas (WEFORUM, 2010). E também no contexto internacional, o país representa uma das 12 nações que abrigam $70 \%$ da biodiversidade total do planeta (IBGE, 2008), tendo alcançado, no ranking global, a condição de $6^{\mathrm{a}}$ economia mundial (BRASIL, 2012). Mas apesar de todas as suas potencialidades, ironicamente, o Brasil continua ícone no ranking dos países mais pobres e desiguais do mundo.

Com este cenário, evidentemente, o ecoturismo no Brasil tende a resultar de uma tensão entre potencialidades/vulnerabilidades, e inúmeros são os riscos de impactos indesejáveis em seu desenvolvimento. Esse argumento pode ser evidenciado também por várias pesquisas realizadas e exemplificadas por estudos de caso, a par- 
tir dos quais é possível afirmar que, de modo geral, a forma como o turismo se desenvolve em áreas naturais tende a gerar mudanças rápidas e, em alguns casos, indesejáveis e irreversíveis (DIEGUES, 1997; PRADO, 2003).

Mas embora haja divergências quanto aos impactos ocasionados no local receptor pelo turismo, é inegável que diferentes culturas interagem no processo, propiciando que visitantes e visitados vivenciem a perspectiva de alteridade. Ainda por esta razão, seria fundamental que os estudos contemporâneos sobre ecoturismo se orientem também por uma perspectiva antropológica (defendida por Steil, 2006), que procure apreender a relação entre turistas e moradores locais segundo um universo de experiências de mediações concretas, no qual se definem e redefinem as identidades culturais. Sob este ponto de vista, as questões de reflexão transcendem aquelas relacionadas aos impactos do turismo sobre as populações locais e de que forma estas podem resistir às transformações que vêm "de fora", e incidem sobre a maneira como os grupos locais e os turistas negociam suas identidades, no ambiente vivenciado. E, neste caso, atores locais e turistas são percebidos como protagonistas e não apenas "produtores" e "consumidores" no processo.

Construindo-se então uma nova perspectiva de conhecimento e prática para o ecoturismo, partindo-se, sobretudo dos debates propostos por Irving (2008) e Moraes (2009), entende-se que, para além do mercado, o turista busca, geralmente, o contraponto com a vivência do dia-a-dia, a oportunidade de experiência integral de valor imaterial, afetivo, simbólico e espiritual, a partir do encontro com a natureza e a cultura de uma localidade, sendo a sociobiodiversidade, e não apenas a natureza em estado virgem, o principal fator inspirador de deslocamento. A partir destes pressupostos não seria mais possível interpretar o ecoturismo apenas como uma atividade econômica e uma viagem orientada para a natureza, mas essencialmente, como um conjunto complexo de práticas sociais, culturais e políticas, orientado pelo comprometimento com os interesses das populações envolvidas, a partir da perspectiva do encontro.

Por esta via de interpretação e sendo o ecoturismo reconhecido, nos anos recentes, como uma importante alternativa para a promoção do desenvolvimento local, muitos autores argumentam que a garantia da participação social no processo se constitui em elemento central para o seu êxito, tendo em vista que este compromisso favoreceria a interação entre diferentes atores sociais locais para a definição e controle do espaço comum e do destino coletivo. No entanto, não se pode ignorar que, nessa relação dialógica, como em qualquer relação humana, ocorrem posturas de poder que incidem e se manifestam em níveis distintos, em função dos interesses, valores e percepções dos envolvidos. Este processo deve assim envolver o respeito ao outro e garantir a representatividade dos diferentes interesses no processo de tomada de decisão, o que significa a adoção de novas formas de construção e ação social coletiva, conforme discutido por Loureiro (2004), no plano das estratégias para a conservação da biodiversidade associado às áreas protegidas, como é o caso de uma RESEX.

Com base nestes argumentos, este artigo reafirma o pressuposto que o ecoturismo pode representar uma alternativa possível para o desenvolvimento local, se os grupos humanos envolvidos forem percebidos como protagonistas no processo e, se 
os benefícios socioeconômicos gerados estiverem vinculados ao compromisso de conservação do patrimônio cultural e natural local, assim como a melhoria de qualidade de vida.

A partir da noção de ecoturismo problematizada até então, em sua associação às Unidades de Conservação ${ }^{9}$ (UCs), é importante lembrar que as áreas naturais protegidas legalmente, constituem "atrativos", tanto para quem vive nessas áreas como para quem as visita, em busca de lazer, contemplação da paisagem, fauna, flora e também vivência de elementos culturais (CEBALLOS-LASCURÁIN, 2002). Sendo assim, no Brasil, um país de megasociobiodiversidade, o ecoturismo tende a representar uma importante alternativa de desenvolvimento para essas áreas, de forte impacto no imaginário global, principalmente no caso amazônico.

Mas para que seja possível entender, especificamente, o contexto do ecoturismo nas RESEX, é importante destacar que estas constituem uma categoria de manejo de UCs concebida a partir das especificidades do próprio país, podendo ser considerada uma tipologia genuinamente brasileira. A formulação desta proposta foi resultante de um panorama histórico de degradação do modo de vida dito tradicional e das pressões, cada vez maiores, sobre a floresta tropical amazônica. E a noção inspiradora para as RESEX surgiu também em decorrência das reivindicações do Movimento Seringueiro (1980), pelo fim da colonização nas áreas dos seringais e, pela concessão destas áreas às populações locais, para que pudesse ser mantida a atividade extrativista, a exemplo do que já acontecia nas terras indígenas. Estas populações, sobretudo na Amazônia Ocidental, em particular no Acre, resistiram fortemente aos processos tradicionais de uso e de ocupação da região, que tendiam a expulsá-los do local onde viviam, por meio de uma organização de base sindical e dos empates ${ }^{10}$ (GONÇALVES, 2003).

A proposta de criação de Reservas Extrativistas na Amazônia, liderada pelos seringueiros, buscou então, conciliar desenvolvimento e proteção da natureza, em um contexto no qual "o seringueiro marca uma relação histórica e cultural com a floresta". (GONÇALVES, 2003, p.11). Sendo assim, a figura da RESEX surgiu como estratégia de apropriação dos recursos naturais e de afirmação de identidades, a partir da relação entre o interesse social e o ambiental. Sua legitimidade provém do fato de ter sido formulada e demandada pelas próprias populações da floresta, (organizadas em torno do Conselho Nacional dos Seringueiros) e de ter sido incorporada pelo poder público, conforme a inspiração inicial.

Segundo o Sistema Nacional de Unidades de Conservação da Natureza (SNUC), instituído pela Lei $n^{\circ}$ 9.985/2000 (BRASIL, 2000 e 2002), a RESEX é considerada uma área protegida utilizada por populações extrativistas tradicionais, cuja subsistência baseia -se no extrativismo e, complementarmente, na agricultura e na criação de animais de pequeno porte, e tem como objetivos básicos proteger os meios de vida e a cultura dessas populações, e assegurar o uso sustentável dos recursos naturais.

Apesar das potencialidades de desenvolvimento da RESEX, muitas críticas sobre o seu processo de consolidação são, até hoje, trazidas à reflexão, com base no argumento de que as iniciativas desenvolvidas para a melhoria de qualidade de vida e para a conservação da biodiversidade não estão ainda articuladas, efetivamente, com as demandas locais. Não obstante, um dos principais desafios, neste caso, é a integração das populações envolvidas aos processos de gestão dos recursos naturais e também à distribuição 
de benefícios, inclusive pela via do ecoturismo, de forma justa e equitativa. Para tanto, o entendimento sobre as RESEXs implica na percepção da complexidade do contexto em que estas se inserem, das transformações socioambientais em curso e dos possíveis efeitos da economia global em seu cotidiano.

\section{A experiência da Reserva Extrativista do Cazumbá-Iracema rumo ao Ecoturismo}

A Reserva Extrativista do Cazumbá-Iracema (RESEX Cl) se localiza em Sena Madureira e Manuel Urbano, no Estado do Acre (Amazônia Ocidental), abrangendo a quase totalidade da micro-bacia do rio Caeté e parte do rio Macauã, tributários do rio laco, afluente do rio Purus (Figura 1). Sua formação vegetal é, predominantemente, de Floresta Ombrófila Aberta, integrando o Corredor Oeste da Amazônia, um dos sete corredores ecológicos propostos para o Brasil (BRASIL, 2007). Sua estrutura de gestão se fundamenta em dois instrumentos principais: um Conselho Deliberativo, criado em 2006, e um Plano de Manejo, oficializado em 2008, que regulamenta as ações propostas para o seu desenvolvimento social e econômico.

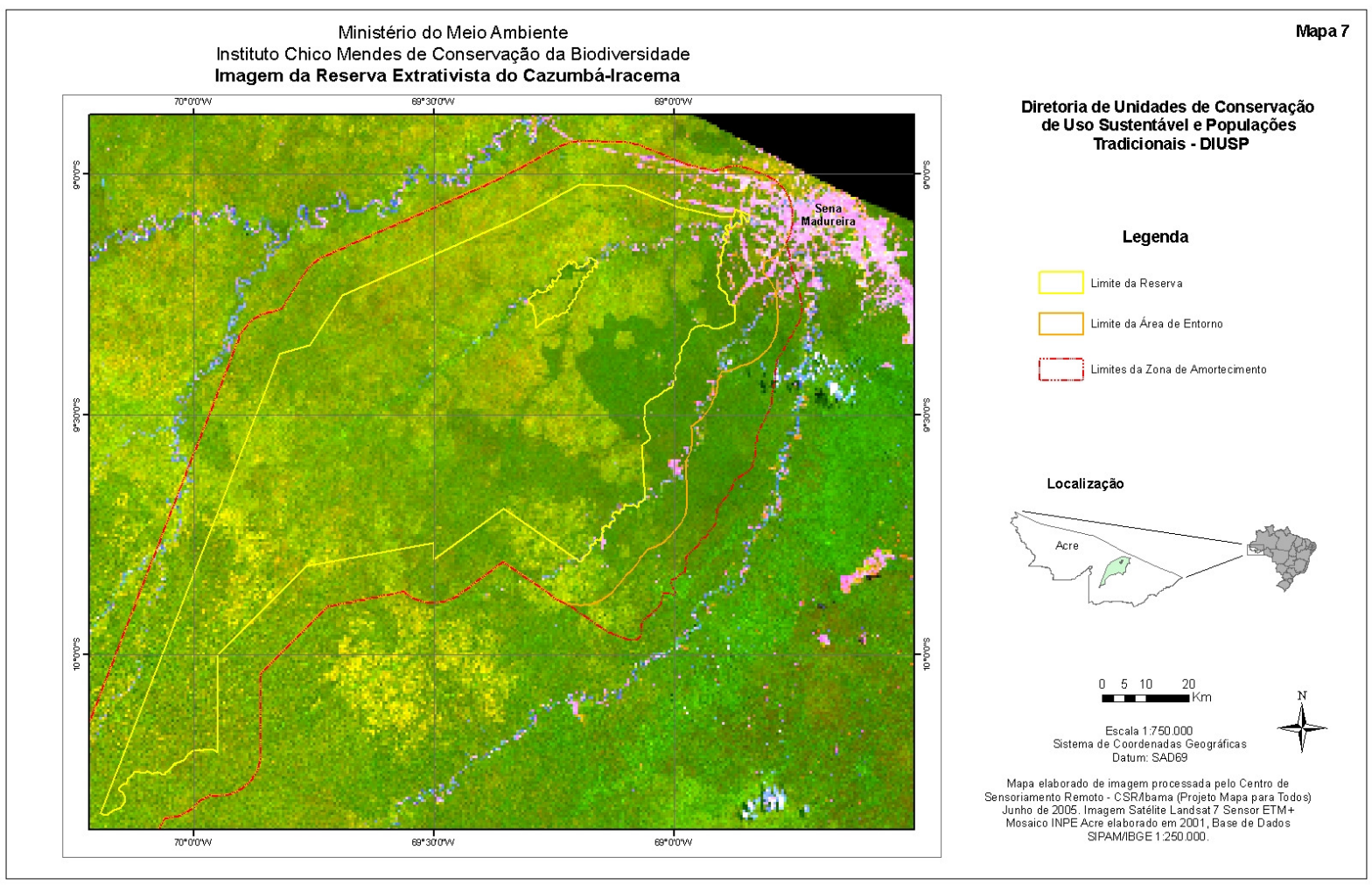

Figura 1: Imagem da RESEX do Cazumbá-Iracema.

Fonte: ICMBio, 2008 (apud MORAES, 2009, p.79).

Figure 1: Picture of the Extrativist Reserve Cazumbá-Iracema.

Source: ICMBio, 2008 (cited in MORAES, 2009, p.79). 
A RESEX Cl é habitada por famílias extrativistas, em sua maioria, migrantes nordestinos e seus descendentes, que foram para o Acre, incentivados pelo governo federal, durante os anos de valorização da borracha, no início do século XX. Sua área (750 mil ha) é dividida em cinco macro-regiões: Cazumbá, Médio Caeté, Alto Caeté, Jacareúba-Redenção e Riozinho-Cachoeira. A macro-região Cazumbá é a que possui o maior número de famílias, sendo que estas, em grande parte, residem em colocações ${ }^{11}$ dos seringais que deram origem à Reserva (BRASIL, 2007). Mas algumas ocupam uma área comunitária: o Núcleo do Cazumbá, foco deste artigo. O Núcleo do Cazumbá, através da sua organização formal, a Associação dos Seringueiros do Seringal Cazumbá (ASSC), foi o principal propulsor para a criação da RESEX Cl, em 2002. Originário dos conflitos fundiários em torno da posse dos seringais da região, o Núcleo do Cazumbá envolve 37 famílias e abriga toda a infraestrutura básica da RESEX (escola, igreja, posto de saúde e alojamento do ICMBio), sendo também o local onde algumas atividades tradicionais são realizadas, coletivamente, por homens e mulheres (BRASIL, 2007). A maioria dos moradores do Núcleo está no local desde o seu nascimento, vivendo quase que exclusivamente de atividades extrativistas (extração da borracha e castanha-do-Brasil), de agricultura familiar, da agropecuária, da caça e da pesca.

No plano do desenvolvimento turístico, em 2002, foi implantada no Núcleo, a primeira pousada da RESEX. E, desde então, se busca ali desenvolver o ecoturismo, de forma ainda embrionária, como uma possível alternativa econômica, sendo esta a única localidade da RESEX onde ocorre visitação. As visitas ocorrem, em geral, no período de inverno, quando há facilidade de deslocamento da cidade de Sena Madureira ao Núcleo do Cazumbá e, envolvem, prioritariamente, o público estudantil e populações da própria região, que buscam conhecer os projetos de desenvolvimento local na UC. No processo de visitação é realizada a divisão de tarefas entre os moradores, para atenderem aos visitantes. Dessa forma, os moradores envolvidos são remunerados pelo serviço prestado. Ocorre que, sendo a visita individual, a renda obtida tende a se concentrar em uma ou duas pessoas, o que gera desconforto entre os demais moradores, uma vez que os envolvidos na organização da visita são sempre os mesmos. Sendo assim, alguns moradores percebem que esse processo beneficia ainda poucas pessoas do local, o que tende a dificultar o desenvolvimento de iniciativas com o objetivo de geração de renda, valorização da cultura local e proteção da natureza, no plano coletivo.

Mas são ainda inúmeros os desafios a serem enfrentados no Núcleo para que o ecoturismo se torne, efetivamente, uma alternativa para o desenvolvimento local. E entre eles, um dos principais é exatamente compreender a perspectiva local sobre o processo, considerando o ponto de vista dos próprios moradores do Núcleo e dos interlocutores institucionais estratégicos envolvidos. Esta é a inspiração da pesquisa descrita neste artigo que buscou responder a duas questões principais: a) Qual a perspectiva presente para o desenvolvimento do ecoturismo? b) Como se projeta o ecoturismo no futuro? 


\section{Ecoturismo em uma perspectiva presente}

Os significados atribuídos, pela maioria dos moradores da RESEX, ao ecoturismo relacionam-se, principalmente, ao seu potencial de geração de renda, valorização da cultura local e contato com a natureza protegida. Neste sentido, sob a percepção local, o ecoturismo não se vincula apenas à conservação dos recursos naturais, mas também à valorização da cultura tradicional. Os moradores da RESEX CI reafirmam ainda ser o ecoturismo uma prática permitida nesta categoria de manejo, conforme prevê o SNUC, desde que esse se desenvolva de acordo com as diretrizes definidas pelos instrumentos de gestão da unidade de conservação. Os interlocutores institucionais pesquisados, por sua vez, vinculam o ecoturismo, principalmente, à conservação da biodiversidade, considerando a relevância do patrimônio natural e a demanda por uma prática de mínimo impacto. Estas leituras parecem estar em sintonia com alguns pressupostos relacionados ao conceito de ecoturismo discutido anteriormente, este entendido como uma prática que incentiva a proteção e a valorização do patrimônio natural e cultural.

Para além dessa visão consensual sobre ecoturismo, este é ainda interpretado pelos sujeitos da pesquisa como uma alternativa para o desenvolvimento local, e não apenas como meio para a geração de renda e/ou conservação da natureza. Pela leitura local, este é também interpretado como uma prática social, que tende a influenciar inúmeras relações entre visitantes e visitados. Esses pressupostos reafirmam a concepção de ecoturismo também como oportunidade de vivência de uma experiência de valor imaterial, afetivo, simbólico e espiritual, a partir do encontro de visitantes com a natureza e a cultura de um lugar, tendo a sociobiodiversidade como fator inspirador para o deslocamento.

O potencial de atrativos do Núcleo do Cazumbá reconhecido pela população local para o desenvolvimento do ecoturismo se sustenta na percepção e valorização do patrimônio natural e cultural, simultaneamente. Os "atrativos" reconhecidos pela própria população local são resumidos a seguir: Horta comunitária de plantas medicinais, Produção Agrícola Familiar (sobretudo a da farinha), Castanhal (castanha - do - Brasil), Criadouros de animais silvestres (queixada e jabuti), Unidade de Produção do Artesanato de borracha, Pousadas Comunitárias, Rio Caeté, Açudes, Estrada de seringa. Estes e outros atrativos identificados na pesquisa estão sistematizados, pedagogicamente, na Figura 2, a partir da vista aérea do Núcleo do Cazumbá. A partir da identificação desses elementos, é possível afirmar que o potencial reconhecido para o ecoturismo na RESEX tende a se vincular, de forma integrada, aos valores culturais e naturais, o que implica, por conseqüência, no reconhecimento da cultura tradicional e na necessidade de uso sustentável dos recursos naturais renováveis.

Mas os interlocutores institucionais pesquisados destacam também, como potencialidades e diferenciais para o desenvolvimento do ecoturismo no local, os aspectos marcantes e peculiares da história de conquista do próprio território acreano e o modo de vida tradicional. Neste caso, e considerando o impacto deste contexto no imaginário sobre a região, a experiência do turista que visita a RESEX poderia gerar uma reflexão cidadã sobre as dificuldades de vida na floresta e do manejo dos recursos naturais renováveis. Assim, o "encontro" entre esses sujeitos tende a inspirar um processo de transformação, subjetivação e reinvenção da realidade. Mas para um intercâmbio real entre "visitantes" e "visitados", Zaoual (2008) salienta que os turistas devem ser responsáveis e solidários em seus intercâmbios com outros mundos. Neste sentido, os moradores do Núcleo reconhecem também a importância, para o turista, em conhecer uma realidade diferente do seu 
Moraes, E.A.; Irving, M.A.

cotidiano, ao lidar com o estranhamento do "exótico" e se sensibilizar para a necessidade de desenvolvimento do destino visitado. E, sendo assim, o próprio intercâmbio e a vivência das experiências geradas na prática do ecoturismo tendem a ser potenciais benefícios resultantes do processo.

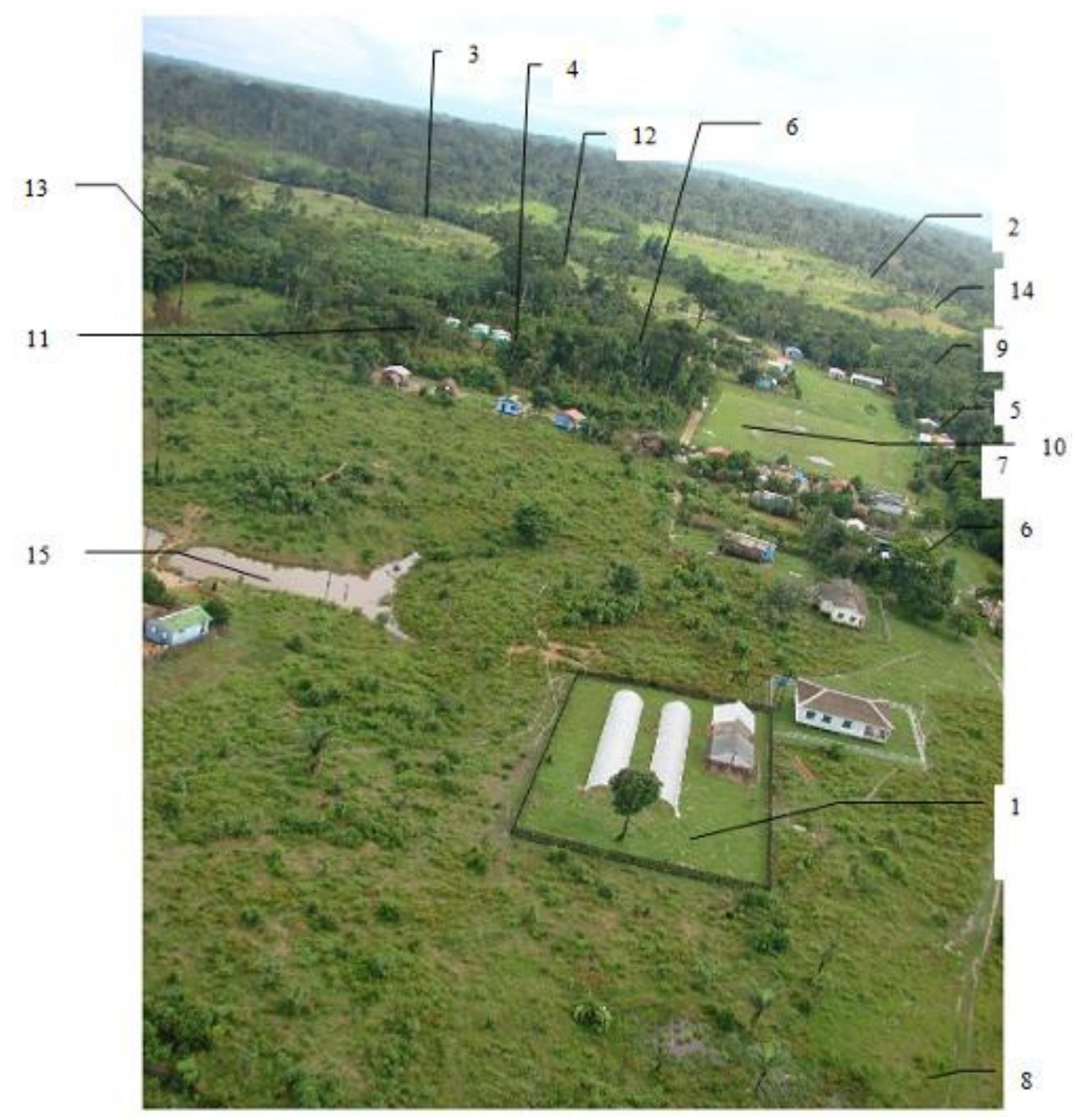

Legenda:
1. Horta de Plantas Medicinais
6. Unidade de Produção de Artesanato
11. Pousada
2. Casa de Farinha
7. Estrada de seringa
12. Criadouro de capivara
3. Castanhal
8. Rio Caeté
13. Trilhas
4. Criadouro de jabuti
9. Porto do Igara
5. Criadouro de queixada
10. Campo de futebol
14. Roçado
15. Açudes

Figura 2: Sistematização dos atrativos reconhecidos pelos moradores do Núcleo Cazumbá.

Fonte: Moraes (2009, p.122).

Figure 2: Systematization of appeal recognized by the residents of the Core Cazumbá.

Source: Moraes (2009, p.122). 
Quanto aos impactos indesejáveis reconhecidos com relação à chegada de visitantes pelos moradores locais, estes estão associados à questão do lixo, à alteração da dinâmica cotidiana, à possibilidade de marginalização das atividades tradicionais, ao surgimento do sentimento de "ganância" na população local, e, a um sentido perverso de homogeneização cultural, imposta pelos padrões capitalistas dominantes na prática do turismo convencional, como anteriormente discutido. Sendo assim, o reconhecimento das normas estabelecidas no Plano de Utilização ${ }^{12}$ da RESEX para o planejamento e a implementação do ecoturismo parece fundamental no processo, bem como a garantia de difusão clara das regras locais aos turistas, para que o intercâmbio de experiência entre turistas e anfitriões não influencie, negativamente, o modo de vida da população local.

Assim, para o Núcleo do Cazumbá, caracterizado por uma organização comunitária ainda incipiente, parece necessária a redefinição de prioridades e o fortalecimento de lideranças para que sejam empreendidas as ações previstas. Sob esta perspectiva, o planejamento e a gestão do ecoturismo, no futuro, devem ser pautados pelos compromissos de capacitação dos atores sociais locais, pelo fortalecimento da organização comunitária e pelo engajamento efetivo da população local no processo de tomada de decisão e controle social nas estratégias adotadas. Nesse sentido, esse processo deve se sustentar nas diversas manifestações culturais locais, e nos modos de se perceber, interpretar e organizar o ecoturismo, considerando-se, sobretudo, os valores imateriais, que integram o modo de vida do Núcleo. Os moradores locais apontam também como dificuldade para o processo, a carência de infraestrutura básica e turística e, a limitação de assistência técnica para a implementação e monitoramento de projetos em curso. Esses obstáculos parecem ainda difíceis de serem superados, se for considerado o apoio incipiente recebido dos órgãos oficiais, com relação às iniciativas de ecoturismo em UCs na Amazônia ${ }^{13}$.

Os interlocutores institucionais da pesquisa, por sua vez, apontam a distância dos centros urbanos, como a principal limitação para a implementação do ecoturismo, uma vez que essa prática, em localidades distantes, exige uma logística complexa e onerosa, como ocorre em outras experiências nas RESEX de Rondônia, Acre, Ceará, Bahia e Pará. Mas por serem recentes, as informações sobre experiências dessa natureza são limitadas e difusas, uma vez que, historicamente, as principais demandas de lazer e turismo estiveram direcionadas às unidades de conservação de proteção integral, como parques nacionais, que têm sido mais emblemáticos no debate sobre ecoturismo na Amazônia. Ainda na perspectiva institucional, a implementação e consolidação dos instrumentos de gestão da UC (Plano de Manejo, Plano de Utilização e Conselho Gestor) parece também essencial, para que se possa definir diretrizes que regulamentem essa prática, de acordo com as suas peculiaridades e demandas. Neste caso, apesar da RESEX Cl dispor desses instrumentos atualizados, estes não contemplam ainda um plano de ação e monitoramento do ecoturismo.

Moradores locais e interlocutores institucionais apontam ainda a necessidade de investimento financeiro, localmente, e pelo olhar institucional, se pode afirmar que os recursos financeiros públicos para a gestão destas áreas são ainda muito limitados, a não ser aqueles advindos de projetos de cooperação internacional. Sendo as- 
sim, parece evidente a necessidade de aporte financeiro do poder público para tais iniciativas, bem como para o próprio processo de efetivação da gestão da RESEX, de acordo com os seus objetivos de manejo e as especificidades de modos de vida das populações extrativistas.

\section{Ecoturismo na projeção de cenários futuros}

A partir da identificação das potencialidades e limitações para o desenvolvimento do ecoturismo no Núcleo do Cazumbá, algumas demandas locais são reafirmadas com este objetivo, na perspectiva futura, como sistematizado nas ações a seguir:

- Formação em associativismo e cooperativismo solidário;

- Especialização técnica em meios de hospedagem e alimentos e bebidas;

- Capacitação em operação logística de transportes e condução de visitantes (manejo de trilha, serviço de emergência médica);

- Realização de estudo de legislação ambiental aplicável as unidades de conservação;

- Capacitação em elaboração e gestão de projetos;

- Capacitação em informática e idiomas.

Evidentemente que este processo tende a envolver também a participação de agentes externos, pelas limitações de recursos humanos e financeiros. Weignand Júnior (2002) salienta também a importância estratégica de integração da população local com equipes técnicas especializadas para que se construa, conjuntamente, a capacidade em planejamento participativo e implementação de projetos. Nesse processo, o estabelecimento de parcerias pode representar um caminho para a concretização das demandas identificadas pelos moradores locais. Sendo assim, os interlocutores institucionais entrevistados reconhecem o seu papel como fundamental para a viabilização do ecoturismo no local.

A Secretaria do Meio Ambiente de Sena Madureira entende, por exemplo, ser a sua atuação potencialmente estratégica, devido à sua atribuição na definição do planejamento e zoneamento territorial do município, lhe competindo investir recursos públicos em infraestrutura básica e turística, no centro urbano e na zona rural. O ICMBio se reconhece também no exercício da função de articulação institucional da RESEX com potenciais parceiros, bem como no apoio e na orientação à população local sobre regulamentação, ordenamento e monitoramento do ecoturismo, de acordo com as normas que regem essa categoria de manejo de UC. E o WWF-BR se afirma como agente potencial para a capacitação da população local, a partir do seu envolvimento na realização de oficinas sobre as etapas metodológicas de planejamento e gestão do ecoturismo. O papel de agente facilitador na formação e capacitação técnica da população local em ecoturismo é reconhecido, da mesma forma, pela Secretaria de Espor- 
te, Turismo e Lazer do Estado do Acre, que vem incentivando iniciativas semelhantes, em outras localidades.

No plano nacional, o Grupo de Trabalho Amazônico e o Conselho Nacional dos Seringueiros percebem o seu papel como mediadores nas negociações entre a população local e os órgãos governamentais (esferas federal e estadual), a cooperação internacional e as ONGs transnacionais. Essas instituições reafirmam também o papel no fomento à discussão sobre projetos para as RESEX, nos conselhos dos órgãos relacionados ao desenvolvimento agrário do país, sendo esses, entendidos como espaços potenciais de negociação para investimentos em projetos de desenvolvimento local. O Conselho Nacional dos Seringueiros entende poder contribuir para o fortalecimento da organização comunitária. A Coordenação geral de RESEX e RDS (atualmente denominada de Gestão Socioambiental/ICMBio/MMA) se identifica como um agente governamental no suporte à elaboração de projetos de desenvolvimento local. E, a coordenação do PROECOTUR/PNE/MMA reconhece o seu papel potencial no apoio técnico à realização de projetos ecoturísticos junto às populações de UCs.

Algumas dessas instituições desenvolvem uma relação estreita com a RESEX $\mathrm{Cl}$ ou no cotidiano da gestão ou por terem participado de projetos conjuntos, o que tende a facilitar a sua articulação com os atores locais para a realização de iniciativas futuras, como a própria elaboração do projeto de ecoturismo da RESEX e, a captação de recursos financeiros para a sua implementação. Para tanto, a definição clara dos diferentes papéis destas instituições implica, fundamentalmente, no engajamento e no comprometimento das mesmas, de forma integrada e sistemática, no cumprimento de suas responsabilidades, para a concretização das decisões coletivas dirigidas ao desenvolvimento do ecoturismo na RESEX. Pelas razões expostas, a pesquisa parece indicar como estratégico o estabelecimento de parcerias e iniciativas colaborativas entre diferentes setores da sociedade civil em rede, para o desenvolvimento efetivo do ecoturismo. Neste sentido, os interlocutores institucionais entrevistados reconhecem a importância do diálogo, envolvendo propostas e estratégias comuns para o ecoturismo, para que este possa ser desenvolvido de forma integrada, intersetorial e interdisciplinar, considerando diferentes escalas de poder de decisão. Mas como já discutido, é fundamental que esta dinâmica seja inspirada, essencialmente, pela ótica dos interesses locais, com base no saber compartilhado, na experiência coletiva e no poder da participação social como via de desconstrução de uma cultura de subordinação para uma lógica de autonomia local.

Segundo a ótica institucional, outro desafio para o desenvolvimento do ecoturismo parece ser a melhoria da cadeia produtiva na RESEX. Para isso, Weignand Júnior (2002) salienta que a população local precisa ter aprimorada a sua capacidade de organização e gestão, com relação às ações coletivas e autogestionárias, ao nível do fortalecimento da associação ou da aplicação de recursos financeiros. Caso contrário, os financiamentos obtidos serão utilizados apenas para a sobrevivência da organização. Neste contexto, o fortalecimento de organização comunitária constitui um desafio central no processo projetual de ecoturismo na RESEX Cl. E apesar das boas intenções, desde a criação da RESEX, a capacidade interna de autogestão e co-gestão de ações que visem à melhoria da qualidade de vida, pelos próprios moradores, continua 
ainda incipiente, o que tende a dificultar a consolidação do processo.

Neste caso, a mobilização dos moradores locais, em conjunto com o ICMBIO com tal objetivo, parece ser um dos caminhos possíveis para se alcançar uma mudança de cenário. Porém, o processo de organização comunitária é longo, necessita de investimento relacional permanente e flexibilidade no planejamento das ações em curso, para a sua efetivação e controle social. É neste sentido que a participação dos moradores do Núcleo do Cazumbá em todo o processo de planejamento, implementação, monitoramento e avaliação do ecoturismo é reafirmada pelos interlocutores institucionais da pesquisa como um diferencial, neste caso estudado. Mas ainda assim, Weignand Júnior (2002, p.34) enfatiza que, "as populações locais necessitam de apoio contínuo para aprenderem como implementar projetos, que viabilizem o alcance dos objetivos propostos e a participação ampla dos envolvidos". Esse autor destaca ainda a importância da organização no período de pós-implementação dessas iniciativas, para o reconhecimento dos méritos, das mudanças positivas, e da necessidade de aperfeiçoamento das práticas em curso, pela própria população local, para que novos resultados possam ser alcançados com a garantia de consolidação daqueles já alcançados com êxito. Para tal, de acordo com os interlocutores institucionais, as lideranças envolvidas devem ter capacidade e sensibilidade para perceber e aceitar as limitações e as potencialidades locais, com relação às novas experiências motivadas pelo desenvolvimento ecoturístico. Nesse processo, as equipes técnicas externas em apoio aos projetos devem também ser flexíveis na execução de determinadas ações previstas e acordadas e estar habilitadas a promover estratégias de participação social e empoderamento da população envolvida, bem como a definir, precisamente, e, conjuntamente com os moradores do Núcleo, os indicadores de avaliação de processo. $\mathrm{O}$ engajamento da população local, por sua vez, é fundamental, sobretudo nas decisões a serem tomadas e na definição de prioridades, segundo os seus códigos culturais e visões de mundo.

Os moradores da RESEX e os interlocutores institucionais pesquisados expressam também uma clara preocupação com a intervenção do empresariado no processo e, o risco de terceirização de serviços nas iniciativas de ecoturismo, uma vez que, nesses moldes, muito provavelmente pouco (ou nada) seria investido na economia local. Isto porque o turismo que gira em torno de megaprojetos de capital (como os resorts e suas derivações) tende a fortalecer as economias dominantes globais e a excluir do processo as camadas sociais menos favorecidas, como é o caso das populações extrativistas na Amazônia.

Também por esta razão, é importante se pensar em instrumentos eficientes para assegurar o protagonismo da população local para que suas próprias demandas sejam consideradas. Para tanto, alguns interlocutores institucionais percebem ser fundamental que as ações para o ecoturismo sejam discutidas e aprovadas, formalmente, pelo Conselho Deliberativo da RESEX e pelos moradores envolvidos diretamente nas iniciativas em andamento. Por este motivo, parece ser importante que se avalie, também, a representatividade e a qualidade de interlocução das populações locais no âmbito do próprio Conselho Deliberativo da RESEX CI. Tal interpretação expressa ainda a necessidade, no futuro, de formação e/ou consolidação de uma câmara técnica 
de ecoturismo para a discussão de questões específicas sobre essa prática no Núcleo do Cazumbá. Além disso, é importante que as iniciativas propostas sejam discutidas no âmbito do Conselho Estadual de Turismo, para que se possa assegurar ações dirigidas à resolução dos problemas identificados, uma prerrogativa essencial para a formulação e a implementação de políticas públicas de turismo na região, em longo prazo. Neste intento, os interlocutores institucionais reconhecem ainda como estratégico que os agentes envolvidos conheçam os compromissos de políticas públicas de proteção da natureza e de turismo, para que possam compreender a sua articulação com as demandas de desenvolvimento local.

Diante destas percepções e significados por ora convergentes, por outras divergentes, mesmo sendo o ecoturismo considerado como uma alternativa possível para o desenvolvimento na RESEX do Cazumbá-Iracema, este não representa ainda uma alternativa de fácil implementação e, muito menos, deve ser entendido como a solução mágica para os problemas enfrentados pela população local. E para que a transformação esperada se efetive, em nível local, com a expectativa de novos horizontes para a população envolvida, é ainda necessário que se avance no sentido de consolidação do ecoturismo, com base no compromisso do uso racional dos recursos naturais renováveis, na compreensão do protagonismo social e no reconhecimento do valor das peculiaridades regionais como diferencial.

\section{Considerações finais}

Do luxo dos "hotéis de selva" à simplicidade dos modos de vida dos povos da floresta até aos banhos de rio e igarapé, o ecoturismo na Amazônia brasileira se desenvolve em meio a contrastes de todos os tipos. Mas a floresta e os modos de vida local deslumbram turistas e tendem a representar importantes inspirações para a geração de alternativas econômicas para as populações que ali residem. Mas apesar desta potencialidade, uma questão merece reflexão: Quem se beneficia efetivamente com o ecoturismo na região? É nesta direção que movimentos sociais e interlocutores da gestão pública discutem alternativas sustentáveis para a subsistência das populações amazônicas, que vivem à margem das políticas públicas. E, sob este prisma, o ecoturismo passa a ser considerado como uma possível alternativa para o desenvolvimento local associado às UCs, sobretudo naquelas que envolvem populações tradicionais.

O estudo sobre a interpretação dos moradores do Núcleo do Cazumbá e dos interlocutores institucionais estratégicos a respeito do processo revela um contexto complexo e associado a inúmeros desafios futuros para o planejamento e gestão dessa prática na RESEX do Cazumbá-Iracema, a médio e longo prazos.

$\mathrm{E}$, no contexto de pesquisa, reafirma-se também a premissa que o ecoturismo sob a ótica local, não se vincula apenas ao compromisso de conservação dos recursos naturais, mas também à compreensão de que a proteção da biodiversidade está condicionada à valorização da cultura e do modo de vida tradicional. Pela via do ecoturismo, a experiência de quem visita a RESEX pode até mesmo trazer à reflexão a compreensão das dificuldades de vida na floresta, resgatando e reinventando as rela- 
ções estabelecidas por e entre homem e natureza.

Não se pode deixar de mencionar que, as unidades de conservação associadas ao modo de vida tradicional, como é o caso das RESEXs, são destinos singulares para uma prática alternativa às formas convencionais de turismo, que, na maioria dos casos, buscam resultados imediatos sem o compromisso com as culturas locais ou com a conservação da biodiversidade e que, portanto, tendem a se tornar insustentáveis no decorrer do tempo, ocasionando desagregação da cultura local e impactos indesejáveis ao patrimônio natural. Mas, neste caso, não bastam apenas sinalizações com mensagens do tipo: "sejam bem vindos!". Diversos obstáculos precisam ainda ser transpostos para o desenvolvimento do ecoturismo na RESEX Cl, como o equacionamento dos problemas de carência de infraestrutura básica e turística, da mobilização comunitária deficiente, e, da limitação de assistência técnica para o acompanhamento, implementação e monitoramento de projetos com este objetivo. Esses obstáculos tornam-se difíceis de serem superados, principalmente, quando se considera o apoio ainda insuficiente dos órgãos governamentais, especificamente no caso daquele dirigido às iniciativas de ecoturismo em UCs na Amazônia brasileira.

Mas ainda assim, a pesquisa tende a indicar que o protagonismo das populações locais na configuração do ecoturismo constitui a garantia para a transformação de sua realidade, o que depende diretamente de se ter como referência quem são os atores envolvidos e do engajamento e articulação social para a construção de seus próprios discursos e práticas ${ }^{14}$.

\section{Referências bibliográficas}

ALEGRETTI, M.H. Reservas Extrativistas: Parâmetros para uma política de desenvolvimento sustentável na Amazônia. In: ANDERSON, A. et al. 0 destino da floresta: reservas extrativistas e desenvolvimento sustentável na Amazônia. Rio de Janeiro: Relume-Dumará, 1994. p. 17-47.

ALVES-MAZZOTTI, A.J.; GEWANDSZNAJDER, F. O método nas ciências naturais e sociais. Pesquisa Quantitativa e Qualitativa. São Paulo: Pioneira Thompson Learning, $2^{\text {a }}$ ed., 2004.

BARDIN, I. Análise de conteúdo. Lisboa: Edições Setenta, 1994.

BUARQUE, S.C. Construindo o desenvolvimento local sustentável - Metodologia de planejamento. Rio de Janeiro: Garamond, 2002.

BRASIL, Ministério da Fazenda. Economia brasileira em perspectiva. 14a Edição Especial. Brasília: Ministério da Fazenda, 2012.

BRASIL. Plano de Manejo da Reserva Extrativista do Cazumbá-Iracema. MMA, ICMBIO, DIUSP, Superintendência do IBAMA no Estado do Acre. Sena Madureira - AC, dezembro de 2007.

BRASIL. Decreto n. 4.340, de 22 de agosto de 2002. Sistema Nacional de Unidades de Conservação da Natureza - SNUC. 4ª Edição. Brasília: MMA/SBF, 2004. 
BRASIL. Lei n. 9.985, de 18 de julho de 2000. Sistema Nacional de Unidades de Conservação da Natureza - SNUC. 4ª Edição. Brasília: MMA/SBF, 2000.

BRASIL. Diretrizes para uma Política Nacional de Ecoturismo. Brasília: EMBRATUR, 1994.

CEBALLOS-LASCURÁIN, H. Introdução: o ecoturismo como fenômeno mundial. In: LINDBERG, K.; HAWKINS, D. E. (Orgs.). Ecoturismo: um guia para planejamento e gestão. São Paulo: Ed. Senac, 2002, p.23-29.

DIEGUES, A.C. O mito moderno da natureza intocada. São Paulo: HUCITEC, 1996.

DIEGUES, A.C. As áreas naturais protegidas, o turismo e as populações tradicionais. In: SERRANO, C., BRUHNS, H. (Orgs.). Viagens à natureza: Turismo, cultura e ambiente. Campinas, SP: Papirus, 1997. (Coleção Turismo), p. 85-101.

FENNEL, D. Ecoturismo, uma introdução. São Paulo: Contexto, 2002.

GONÇALVES, C.W.P. Geografando nos varadouros do mundo: da territorialidade seringalista (o seringal) à territorialidade seringueira (a Reserva Extrativista). Brasília: IBAMA, 2003.

IBGE Instituto Brasileiro de Geografia e Estatística. Indicadores de Desenvolvimento Sustentável Brasil 2008. Estudos e Pesquisas Informação Geográfica, número 5. Rio de Janeiro: IBGE, 2008.

IRVING, M.A. Ecoturismo em Áreas Protegidas: Da Natureza ao Fenômeno Social. In: COSTA, N.M.C; NEIMAN, Z.; COSTA, V.C. Pelas trilhas do Ecoturismo. São Carlos: Editora RIMA, 2008, p.3-15.

IRVING, M.A. Áreas Protegidas de fronteira e turismo sustentável na Amazônia: entre o surrealismo e a invenção. Revista de Desenvolvimento Econômico. Salvador, Ano VIII, No 13, 2006.

IRVING, M.A. Áreas Protegidas e Inclusão Social: Construindo novos significados. Rio de Janeiro: Editora Aquarius, 2006.

LOUREIRO, C.F. Educar, participar e transformar em educação ambiental. Revista Brasileira de Educação Ambiental. Brasília, Ano I, No 0, 2004, p. 13-20.

MORAES, E.A. Encontro na Floresta: Interpretando o Ecoturismo sob a ótica local na Reserva Extrativista do Cazumbá-Iracema (Acre-Brasil). Rio de Janeiro: UFRJ. Programa Eicos - Mestrado, 2009.

MORAES, E.A.; IRVING, M.A. Ecoturismo em reservas extrativistas na Amazônia: avanços e desafios. II Encontro de Ecoturismo em Unidade de Conservação e I Congresso Nacional de Ecoturismo, 2007. Itatiaia. Anais... Itatiaia: Physis, 2007 (CD ROOM).

MURRIETA, J.R.; RUEDA, R.P. Gestão das Reservas Extrativistas. In: UICN, Reservas Extrativistas. Gland, Suíça e Cambridge, Reino Unido. SADAG, Bellegarde-surValserien. France, 1995.

PIRES, P.S. Dimensões do Ecoturismo: uma investigação conceitual. São Paulo: Editora SENAC São Paulo, 2002. 
PRADO, R. Tensão no Paraíso: Aspectos da Intensificação do Turismo na llha Grande. 7ª Edição. Caderno Virtual de Turismo - LTDS/COPPE/UFRJ (Março, 2003).

STEIL, C. Antropologia do Turismo: comunidade e desterritorialização. In: PERALTA, E.; ANICO, M. (Org.). Patrimônios e Identidades. Ficções contemporâneas. Oeiras: Celta Editora, 2006, p. 163-170.

WEFORUM. The Global Competitiveness Report 2010-2011. World Economic Forum, 2010, p. 32. Disponível em http://www3.weforum.org/docs/ WEF GlobalCompetitivenessReport 2010-11.pdf. Acesso em 01 de outubro de 2012.

WEIGNAND-JR, R. Por que as atuais linhas de financiamento limitam o desenvolvimento comunitário sustentável em reservas extrativistas. Revista Participe. Porto Alegre, 2002.

ZAOUAL, H. Do turismo de massa ao turismo situado: quais as transições? Caderno Virtual de Turismo. Rio de Janeiro: Vol. 8, N², 2008.

\begin{abstract}
Notas
${ }^{1}$ Disponível em http://360graus.terra.com.br/ecoturismo/default.asp? did=27343\&action=reportagem.

${ }^{2}$ Diegues (1996) explica que o mito supõe a incompatibilidade entre as ações de quaisquer grupos humanos e a conservação da natureza.

${ }^{3}$ Esta técnica consiste em identificar uns poucos sujeitos e pedir-lhes que indiquem outros, os quais, por sua vez, indicarão outros e assim sucessivamente, até que se atinja o ponto de redundância.

${ }^{4}$ Em 2011, a RESEX Cl passou a se vincular a Coordenação Regional de Porto Velho.

${ }^{5} \mathrm{Em}$ 2010, a DIUSP passou a ser denominada de Coordenação Geral de Gestão Socioambiental.

${ }^{6}$ Época de publicação do Relatório Nosso Futuro Comum, em que o movimento ambientalista conquista muitos adeptos a favor da proteção da natureza e a questão ambiental passa a fazer parte das preocupações de diferentes instâncias políticas e da agenda dos grandes temas estratégicos mundiais.

${ }^{7} \mathrm{~A}$ concepção predominante de turismo influenciada pela dinâmica capitalista, principalmente até a década de 1970 (com rebatimentos até a atualidade, centrada na lógica do mercado), se baseia na compra e venda de produtos e serviços padronizados, com forte apelo comercial, privilegiando o lucro e a escala de massa, tendo como consequências inúmeros impactos indesejáveis com relação à autenticidade dos lugares turísticos e aos processos de proteção da natureza.
\end{abstract}

${ }^{8}$ Adotou-se a perspectiva de Buarque (2002) que entende desenvolvimento local como um longo processo endógeno de mudança, que leva ao dinamismo econômico e à melhoria de vida de populações de pequenas unidades territoriais. Essas mudanças são, sobretudo, qualitativas para que uma determinada comunidade possa autogerir-se, sendo estimulado e fortalecido o seu potencial social, cultural, econômico, ambiental e político. Nesse caso, os recursos endógenos são entendidos sempre como ponto de partida e nunca 
como ponto de chegada.

${ }^{9}$ Espaço territorial e seus recursos ambientais, incluindo as águas jurisdicionais, com características naturais relevantes, legalmente instituído pelo poder público, com objetivos de conservação e limites definidos, sob regime especial de administração do qual aplicam garantias adequadas de proteção (BRASIL, 2000).

${ }^{10}$ Os empates eram manifestações das famílias seringueiras que se reuniam rumo à floresta, para tentar conter ações de devastação da natureza e garantir a suspensão da atividade predatória.

${ }^{11}$ Unidades habitacionais definidas pelo número e extensão das estradas de seringa, estabelecidas em função da localização das seringueiras.

${ }^{12} \mathrm{O}$ Plano de Utilização é o documento de base do Plano de Manejo, consistindo no conjunto de regras internas construídas, definidas e compactuadas pela população da UC, quanto às atividades tradicionalmente praticadas, o manejo dos recursos naturais renováveis, o uso e ocupação da terra e a conservação ambiental, considerando-se a legislação vigente.

${ }^{13}$ Os dados obtidos nos levantamentos de campo indicam que há uma sensação de distanciamento do poder público com relação às ações desenvolvidas no local. Isto ocorre apesar do desenvolvimento, na década de 2000, do PROECOTUR. Apesar de elevados investimentos deste Programa, pouco se reconhece de seus efeitos em benefício dos interesses locais.

${ }^{14}$ Este artigo é derivado de dissertação de mestrado.

Edilaine Albertino de Moraes: Universidade Federal de Juiz de Fora, Juiz de Fora, MG, Brasil.

Email: edilainerumos@yahoo.com.br

Link para o currículo Lattes: http://lattes.cnpq.br/5450933897214464

Marta de Azevedo Irving: Universidade Federal do Rio de Janeiro, Rio de Janeiro, RJ, Brasil.

Email: marta.irving@mls.com.br

Link para o currículo Lattes: http://lattes.cnpq.br/1912229324377473

Data de submissão: 1ํ de maio de 2013

Data de recebimento de correções: 15 de maio de 2013

Data do aceite: 08 de junho de 2013

Avaliado anonimamente 